\title{
Melatih keterampilan siswa SMP dalam menggunakan Microsoft Office dan PhET
}

\author{
Hikmawati ${ }^{1}$, Julia Izni Malika ${ }^{1}$, Firda Aprilia Insani ${ }^{1}$, Nur Rahmah ${ }^{1}$, Paramita Suhartanti ${ }^{1}$ \\ ${ }^{1}$ FKIP, Universitas Mataram, Mataram, Indonesia.
}

DOI: $\underline{10.29303 / \text { ujcs.v2i4.154 }}$

\section{Article Info}

Received: November 21, 2021

Revised: December 20, 2021

Accepted: December 26, 2021

\begin{abstract}
Abstrak: Keterampilan dalam menjalankan program komputer menjadi hal penting bagi siswa sehingga mereka mampu belajar dan bekerja sesuai dengan perkembangan teknologi, informasi, dan komunikasi. Tujuan kegiatan pengabdian kepada masyarakat ini adalah untuk melatih keterampilan siswa SMP dalam menggunakan Microsoft Office dan PhET. Kegiatan ini dilakukan di SMPN 19 Mataram selama 8 minggu, mulai dari tanggal 27 September hingga 21 November 2021 . Kegiatan ini merupakan bagian dari program Kampus Mengajar Angkatan 2. Metode pelaksanaan kegiatan yaitu: perencanaan, pelaksanaan, dan evaluasi kegiatan. Pada tahap perencanaan kegiatan, tim melakukan koordinasi dan berdiskusi dengan dosen pembimbing, guru mata pelajaran (TIK dan IPA), dan kepala sekolah. Pada tahap pelaksanaan kegiatan, tim melatih siswa dalam menggunakan aplikasi perangkat lunak yaitu Microsoft Office dan PhET. Aplikasi di dalam Microsoft Office yang dipilih untuk dilatihkan kepada siswa adalah Excel, Word, dan PowerPoint. Sementara itu, Simulasi PhET yang diajarkan ke siswa adalah topik Listrik Statis. Jadwal pelaksanaan pelatihan untuk Microsoft Office menggunakan waktu mata pelajaran TIK, sedangkan untuk PhET menggunakan waktu mata pelajaran IPA. Pada tahap evaluasi kegiatan, tim bersama dengan dosen pembimbing melakukan identifikasi kendala-kendala yang dialami dan upaya perbaikan yang dilakukan di tiap minggu. Tim juga melakukan koordinasi dan diskusi dengan guru mata pelajaran TIK, guru mata pelajaran IPA, dan kepala sekolah tentang rencana tindak lanjut dari kegiatan pelatihan. Pelatihan yang diberikan oleh tim tentang adaptasi teknologi berupa penggunaan aplikasi perangkat lunak ini telah meningkatkan keterampilan siswa SMP dalam menggunakan program komputer yaitu Microsoft Office dan PhET.
\end{abstract}

Kata Kunci: kampus mengajar; Microsoft Office; PhET.

Abstract: Skills in running computer programs are important for students so that they are able to learn and work in accordance with developments in technology, information, and communication. The purpose of this community service activity is to train junior high school students' skills in using Microsoft Office and PhET. This activity was carried out at SMPN 19 Mataram for 8 weeks, starting from September 27 to November 21, 2021. This activity is part of the Campus Teaching Program Batch 2. The methods of implementing the activities are: planning, implementing, and evaluating activities. At the activity planning stage, the team coordinated and discussed with supervisors, subject teachers (ICT and Science), and school principals. At the activity implementation stage, the team trained students in using software applications, namely Microsoft Office and PhET. Applications in Microsoft Office that are chosen to be trained to students are Excel, Word, and PowerPoint. Meanwhile, PhET Simulation taught to students is the topic of Static Electricity. The training schedule for Microsoft Office uses ICT subject time, while for PhET uses Science subject time. At the activity evaluation stage, the team together with the supervisors identify the obstacles experienced and the improvement efforts made every week. The team also coordinated and discussed with ICT subject teachers, science teachers, and school principals about the follow-up plan of the training activities. The training provided by the team on technology adaptation in the form of using software applications has improved the skills of junior high school students in using computer programs, namely Microsoft Office and PhET.

Keywords: teaching campus; Microsoft Office; PhET.

Citation: Hikmawati, H., Malika, J. I., Insani, F. A., Rahmah, N., \& Suhartanti, P. (2021). Melatih keterampilan siswa SMP dalam menggunakan Microsoft Office dan PhET. Unram Journal of Community Service, 2(4), 105-110. https://doi.org/10.29303/ujcs.v2i4.154 


\section{Pendahuluan}

Di abad ke-21 ini, dunia mengalami perubahan yang sangat cepat. Perubahan ini menyangkut di segala lini kehidupan, yaitu bidang ekonomi, transportasi, teknologi, komunikasi, informasi, dan lain-lain. Perubahan ini perlu diantisipasi dengan menguasai keterampilan abad ke-21. Keterampilan abad ke-21 ini meliputi berpikir kritis dan pemecahan masalah, kreativitas dan inovasi, komunikasi, dan kolaborasi. Pengembangan keterampilan abad ke-21 ini dapat dilakukan pada semua disiplin (Redhana, 2019). Keterampilan ini perlu di implementasikan guru dalam proses pembelajaran agar kualitas pembelajaran meningkat (Junedi et al., 2020).

Ketika siswa bermain dengan teman sebayanya, siswa akan secara alami melakukan interaksi sosial dengan temannya. Sering mengajak siswa berkomunikasi memberikan dampak positif untuk mengembangkan kemampuan berkomunikasi anak. Hal ini akan menstimulasi otak anak untuk mencontoh penggunaan kalimat yang baik. Selain itu keterampilan abad ke-21 siswa dilatih untuk menjelaskan dan bertukar informasi dengan temannya ketika proses pembelajaran berlangsung, belajar cara menyampaikan informasi dengan benar, sehingga dapat dimengerti dan dipahami oleh temannya. Peran guru disini adalah sebagai fasilitator. Keterampilan abad ke-21 dapat menumbuhkan dan meningkatkan kerjasama dalam suatu kelompok untuk menyelesaikan masalah tertentu, meningkatkan rasa toleransinya terhadap perbedaan pendapat teman, berusaha untuk berpikir kritis dan kreatif untuk memecahkan permasalahan tentang mengkaitkan sesuatu (Septikasari, 2018).

Dengan demikian, sistem pendidikan harus dapat menghasilkan peserta didik milenial yang mampu bersaing dalam menghadapi era industri 4.0 yang semua berbasis digital. Usulan Menteri Pendidikan dan Kebudayaan Republik Indonesia, Nadiem Anwar Makarim, tentang Merdeka BelajarKampus Merdeka (MB-KM) adalah untuk mengubah pola lama dalam pendidikan yang hanya mementingkan penguasaan materi saja yang berakibat peserta didik tidak dapat berfikir kritis dan inovatif. Merdeka belajar memiliki makna bahwa unit pendidikan atau sekolah, guru dan muridnya mempunyai kebebasan untuk berinovasi, belajar dengan mandiri, dan kreatif (Darmayani, 2020).

Mendikbud membuat kebijakan baru tentang konsep Merdeka Belajar telah menyebabkan berbagai persepsi pada semua kalangan masyarakat, termasuk guru (Widyastuti, 2020). Kebijakan MB-KM memiliki tujuan untuk meningkatkan kompetensi lulusan, sehingga siswa menjadi lulusan yang unggul dan berkepribadian serta dapat bersaing secara global sesuai tuntutan zaman (Sudaryanto et al., 2020).

Di era Revolusi Industri 4.0 kebutuhan utama yang ingin dicapai dalam sistem pendidikan atau lebih khusus dalam metode pembelajaran adalah siswa dapat menguasai literasi baru dan penguatan pendidikan karakter (Yamin \& Syahrir, 2020). Merdeka Belajar yang tercermin dalam kompetensi profesional guru diantaranya adalah guru menyampaikan materi pembelajaran dengan dengan jelas serta menggunakan tekhnologi, informasi dan komunikasi, serta aplikasi materi dalam kehidupan sehari-hari. Dengan demikian para siswa dapat memperoleh ilmu dari penguasaan materi oleh guru yang tidak hanya dari satu sumber seperti buku, melainkan dari berbagai sumber lain sehingga membuat kelas terasa menyenangkan (Pendi, 2020).

Bentuk pelaksanaan MB-KM adalah Program Kampus Mengajar yang bertujuan untuk menanamkan empati mahasiswa terhadap permasalahan kehidupan masyarakat, mampu bekerja bersama lintas bidang ilmu, serta meningkatkan peran dan kontribusi nyata perguruan tinggi dan mahasiswa dalam pembangunan nasional. Program ini berupa asistensi mengajar untuk memberdayakan mahasiswa dalam membantu proses pembelajaran di sekolah. Aktivitas mahasiswa dalam program ini adalah membantu pembelajaran literasi dan numerasi, membantu administrasi, dan membantu adaptasi teknologi (Nurhasanah \& Heni, 2020).

Kegiatan mahasiswa dalam membantu adaptasi teknologi dapat berupa kegiatan melatih siswa dalam menggunakan aplikasi komputer. Keterampilan dalam menjalankan program komputer menjadi hal penting bagi siswa sehingga mereka mampu belajar dan bekerja sesuai dengan perkembangan teknologi, informasi, dan komunikasi. Tujuan kegiatan pengabdian kepada masyarakat ini adalah untuk melatih keterampilan siswa SMP dalam menggunakan Microsoft Office dan PhET.

\section{Metode}

Kegiatan pengabdian kepada masyarakat ini merupakan bagian dari program Kampus Mengajar Angkatan 2. Lokasi kegiatan ini bertempat di SMPN 19 Mataram. Kegiatan pengabdian kepada masayarakat ini dilaksanakan selama 8 minggu yang dimulai sejak tanggal 27 September sampai dengan 21 November 2021. Rincian jadwal kegiatan pengabdian kepada masyarakat ditunjukkan Tabel 1. 
Tabel 1. Rincian Jadwal Kegiatan

\begin{tabular}{|c|c|c|}
\hline Minggu & Tanggal Pelaksanaan & Keterangan \\
\hline 1 & 27 September - 2 Oktober 2021 & $\begin{array}{l}\text { Koordinasi dengan dosen pembimbing, guru mata pelajaran TIK dan IPA, } \\
\text { serta Kepala Sekolah }\end{array}$ \\
\hline 2 & 4-9 Oktober 2021 & Membuat rundown acara pelatihan \\
\hline 3 & 11-16 Oktober 2021 & Pengenalan dan Latihan menggunakan Microsoft word \\
\hline 4 & 18-23 Oktober 2021 & $\begin{array}{l}\text { Latihan menggunakan Microsoft word, pengenalan dan Latihan } \\
\text { menggunakan Microsoft excel }\end{array}$ \\
\hline 5 & 25-30 Oktober 2021 & $\begin{array}{l}\text { Latihan menggunakan Microsoft word dan Microsoft excel, serta pengenalan } \\
\text { dan Latihan menggunakan PhET }\end{array}$ \\
\hline 6 & 1-6 November 2021 & $\begin{array}{l}\text { Latihan menggunakan Microsoft word dan Microsoft excel, pengenalan dan } \\
\text { Latihan menggunakan Microsoft powerpoint }\end{array}$ \\
\hline 7 & 8-13 November 2021 & Latihan menggunakan Microsoft word, Microsoft excel, Microsoft powerpoint \\
\hline 8 & 15-21 November 2021 & Rencana tindak lanjut kegiatan pelatihan Microsoft Office dan PhET \\
\hline
\end{tabular}

Metode pelaksanaan kegiatan terdiri atas tiga tahapan yaitu: tahapan perencanaan, pelaksanaan, dan evaluasi kegiatan. Pada tahap perencanaan kegiatan, tim melakukan koordinasi dan berdiskusi dengan dosen pembimbing, guru mata pelajaran TIK, guru mata pelajaran Sains, dan kepala sekolah SMPN 19 Mataram. Pada tahap awal ini, tim juga melakukan observasi kemampuan awal siswa tentang TIK dan laboratorium virtual.

Pada tahap pelaksanaan kegiatan, tim melatih siswa dalam menggunakan aplikasi perangkat lunak yaitu Microsoft Office dan PhET. Aplikasi di dalam Microsoft Office yang dipilih untuk dilatihkan kepada siswa adalah Excel, Word, dan PowerPoint. Sementara itu, Simulasi PhET yang diajarkan ke siswa adalah topik Listrik Statis. Jadwal pelaksanaan pelatihan untuk aplikasi Microsoft Office menggunakan waktu mata pelajaran TIK, sedangkan untuk aplikasi PhET menggunakan waktu mata pelajaran Sains.

Pada tahap evaluasi kegiatan, tim bersama dengan dosen pembimbing melakukan identifikasi kendala-kendala yang dialami dan upaya perbaikan yang dilakukan di tiap minggu. Tim juga melakukan koordinasi dan diskusi dengan guru mata pelajaran TIK, guru mata pelajaran sains, dan kepala sekolah tentang rencana tindak lanjut dari kegiatan pelatihan.

\section{Hasil dan Pembahasan}

\section{Hasil}

Minggu 1 (27 September - 2 Oktober 2021): Mendiskusikan jadwal, waktu, tempat dan mekanisme pelaksanaan pelatihan Microsoft Office dan PhET dengan dosen pembimbing, guru pelajaran TIK dan guru pelajaran Sains, serta Kepala Sekolah.

Minggu 2 (4-9 Oktober 2021): Membuat rundown program bantuan pengoperasian Microsoft Office (Word, excel, powerpoint). Bantuan adaptasi teknologi melalui pengoperasian Microsoft Office akan mulai dilaksanakan minggu depan untuk semua siswa mulai dari kelas VII, VIII, dan IX. Bantuan ini akan dilaksanakan selama 6 kali pertemuan setiap kelas, dimana setiap pertemuan waktunya adalah satu jam. Tim berencana akan menggunakan bantuan modul, proyektor, dan laptop. Hasil membuat rundown program bantuan pengoperasian Microsoft Office ditunjukkan Gambar 1.

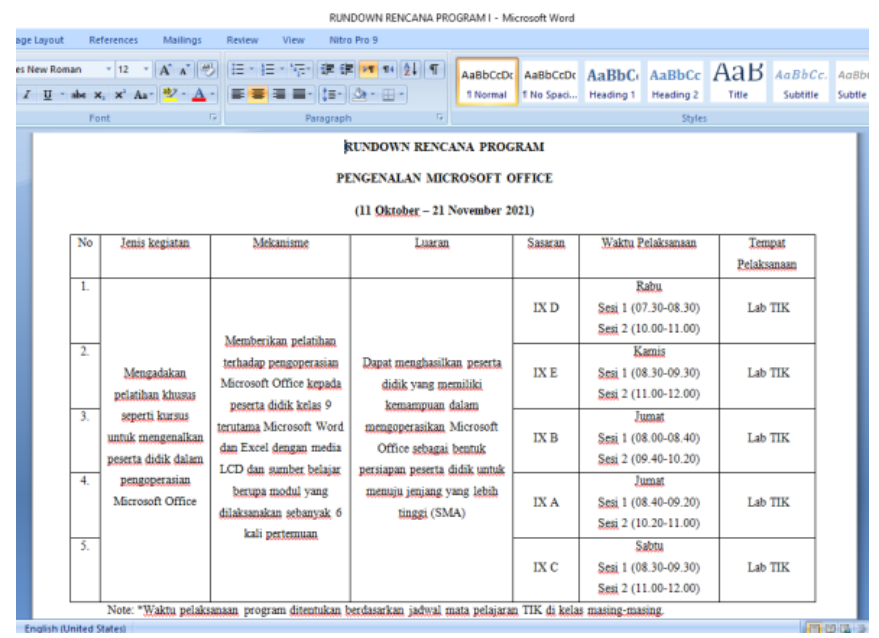

Gambar 1. Rundown program bantuan pengoperasian Microsoft Office

Pengenalan simulasi PhET pada siswa akan dilakukan di mata pelajaran IPA bab Listrik Statis dan Listrik Dinamis kelas IX. Rencananya, simulasi yang akan digunakan adalah simulasi hukum Coulomb, hukum Ohm, dan simulasi lainnya dengan menyesuaikan dengan materi dan waktunya. Pemilihan materi yang berhubungan dengan Fisika tersebut adalah karena simulasi untuk materi Biologi sangat sedikit dan terbatas.

Minggu 3 (11-16 Oktober 2021): Berdasarkan observasi awal tentang kemampuan TIK, siswa masih belum terbiasa dan kaku dalam menggunakan komputer. Mereka belum tahu cara membuka software, cara menyalakan dan mematikan komputer, serta belum terbiasa dengan penggunaan mouse dan tomboltombol keyboard. Dalam hal pengoperasian Microsoft Word, siswa kelas IX sebelumnya sudah pernah 
praktek membuat biodata sederhana melalui perangkat smartphone. Namun, tentu saja ada banyak perbedaan dalam pengoperasiannya pada komputer dan smartphone. Melalui bantuan adaptasi teknologi yang tim berikan, siswa dibantu untuk mengoperasikan perangkat keras dan perangkat lunak komputer, terutama Microsoft Office. Pada minggu ini, dalam hal pengoperasian Ms Word, siswa sudah mengetahui cara menggunakan mouse, mengenali fungsi tombol keyboard dan shortcutnya, membuka software (aplikasi), membuat biodata diri, membuat gambar dan bentuk, serta membuat tabel. Siswa juga mulai memahami fungsi setiap ribbon pada menu Home dan Insert. Sementara itu, dalam hal pengoperasian Ms Excel, siswa mampu membuat tabel berisi data sederhana dan mengolah data array pada tabel tersebut, seperti mencari rata-rata (average), mencari total data (sum), mencari nilai maksimum (max), nilai minimum (min), dan cara mengurutkan (sort) data.

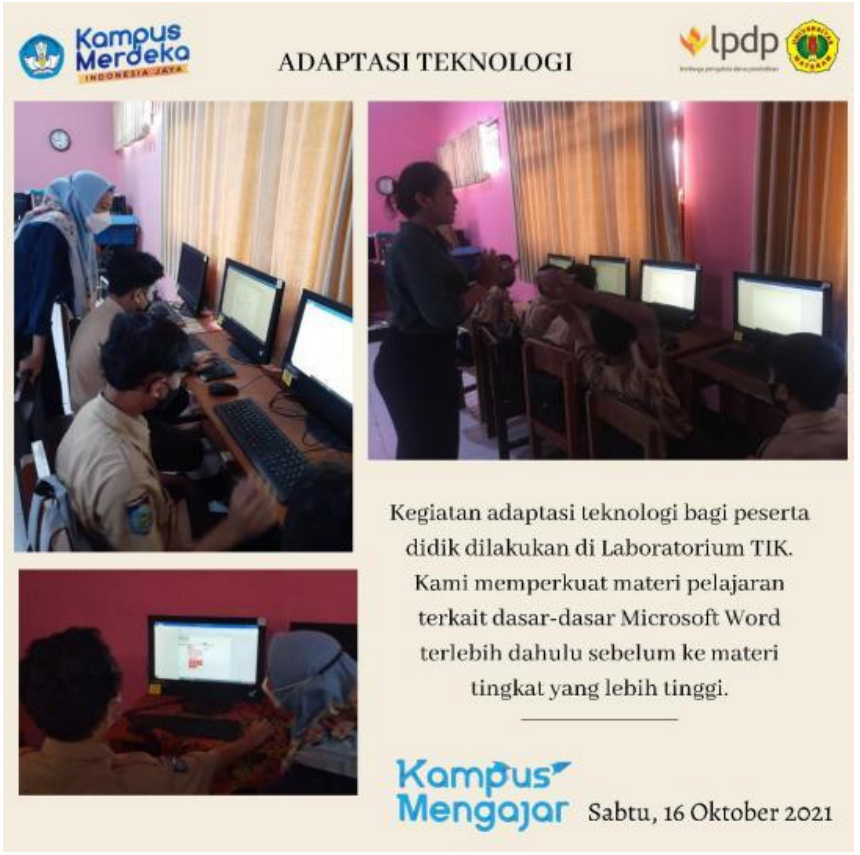

Gambar 2. Pelatihan Microsoft Office

Hambatan lain yang tim rasakan adalah pada saat pengoperasian komputer. Mayoritas siswa takut dan ragu setiap kali hendak menekan tombol-tombol pada keyboard. Solusi untuk mengatasi rasa takut tersebut adalah memberikan kalimat-kalimat ajakan dan motivasi untuk terus mencoba dan tidak takut salah. Tim juga meyakinkan siswa bahwa setiap kesalahan dapat diulang dengan menggunakan menu undo $(\mathrm{Ctrl}+\mathrm{Z})$.

Minggu 4 (18-23 Oktober 2021): Berbeda dengan minggu sebelumnya dimana siswa belum dapat mengoperasikan komputer, kini siswa sudah mampu menyalakan dan mematikan komputer, menggerakkan dan menggunakan mouse, mengenali fungsi tombol keyboard dan shortcutnya, serta membuka software sendiri. Pada minggu ini, dalam hal pengoperasian Ms Word, siswa sudah mengetahui cara membuat tabel, bentuk, dan equation. Siswa juga mulai memahami fungsi setiap ribbon pada menu Home dan Insert. Sementara itu, dalam hal pengoperasian Ms Excel, siswa mampu membuat tabel berisi daftar nilai, mengolah data array pada tabel tersebut, seperti mencari rata-rata (average), dan mencari total data (sum). Keterampilan mengolah data tersebut juga sekaligus dapat meningkatkan kemampuan numerasi siswa.

Minggu 5 (25-30 Oktober 2021): Siswa sudah mampu menyimpan data pada Ms Word dan Ms Excel sendiri tanpa bantuan tim. Melalui bantuan adaptasi teknologi dalam pengoperasian Ms Office ini, selain lebih terbiasa dengan teknologi, siswa juga dapat meningkatkan keterampilan numerasi mereka melalui pengolahan data sederhana. Pada minggu 5 ini, siswa kelas IX mulai dikenalkan pada laboratorium virtual $\mathrm{PhET}$. Melalui penggunaan simulasi atau laboratorium virtual PhET, konsep-konsep yang bersifat abstrak dapat disampaikan secara kongkret dengan fakta-fakta yang dapat diamati oleh siswa secara langsung. Dalam hal ini, konsep abstrak yang diajarkan adalah muatan listrik dan interaksinya, serta gaya yang timbul akibat muatan listrik (gaya Coulomb). Selain itu, simulasi yang disediakan oleh PhET sangat interaktif, sehingga siswa dapat mengeksplorasi secara langsung pemahaman mereka. Simulasi PhET yang digunakan pada minggu ini sehubungan dengan materi Listrik Statis adalah Balloons and Static Electricity untuk mengetahui ineteraksi antar muatan, perpindahan muatan, dan muatan induksi, serta simulasi Coulomb's Law untuk memvisualisasikan gaya elektrostatis yang dihasilkan oleh dua muatan, dan hubungan antara gaya tersebut dengan jarak dan besar muatan. Dengan menggunakan simuasi PhET, pemahaman konsep dan minat siswa dalam mata pelajaran IPA meningkat. Siswa menjadi lebih mudah dalam memahami konsepkonsep yang diberikan. Pembelajaran IPA juga menjadi lebih menyenangkan dan tidak membosankan. Kegiatan pengenalan PhET pada minggu 5 ini ditunjukkan Gambar 3.

Minggu 6 (1-6 November 2021): Siswa menunjukkan antusiasme yang tinggi setiap berada di lab komputer. Terdapat peningkatan yang signifikan pada diri siswa dalam mengoperasikan komputer, Ms Office word maupun excel tanpa bantuan tim. Pada minggu ini, beberapa siswa kelas IX sudah mulai diajarkan dasar-dasar Ms Powerpoint dan sudah mampu menghasilkan presentasi sederhana berupa biodata diri. Pada minggu ini, tim juga melanjutkan pengenalan siswa kelas IX pada laboratorium virtual 
PhET, masih pada topik atau materi yang sama yaitu Listrik Statis.

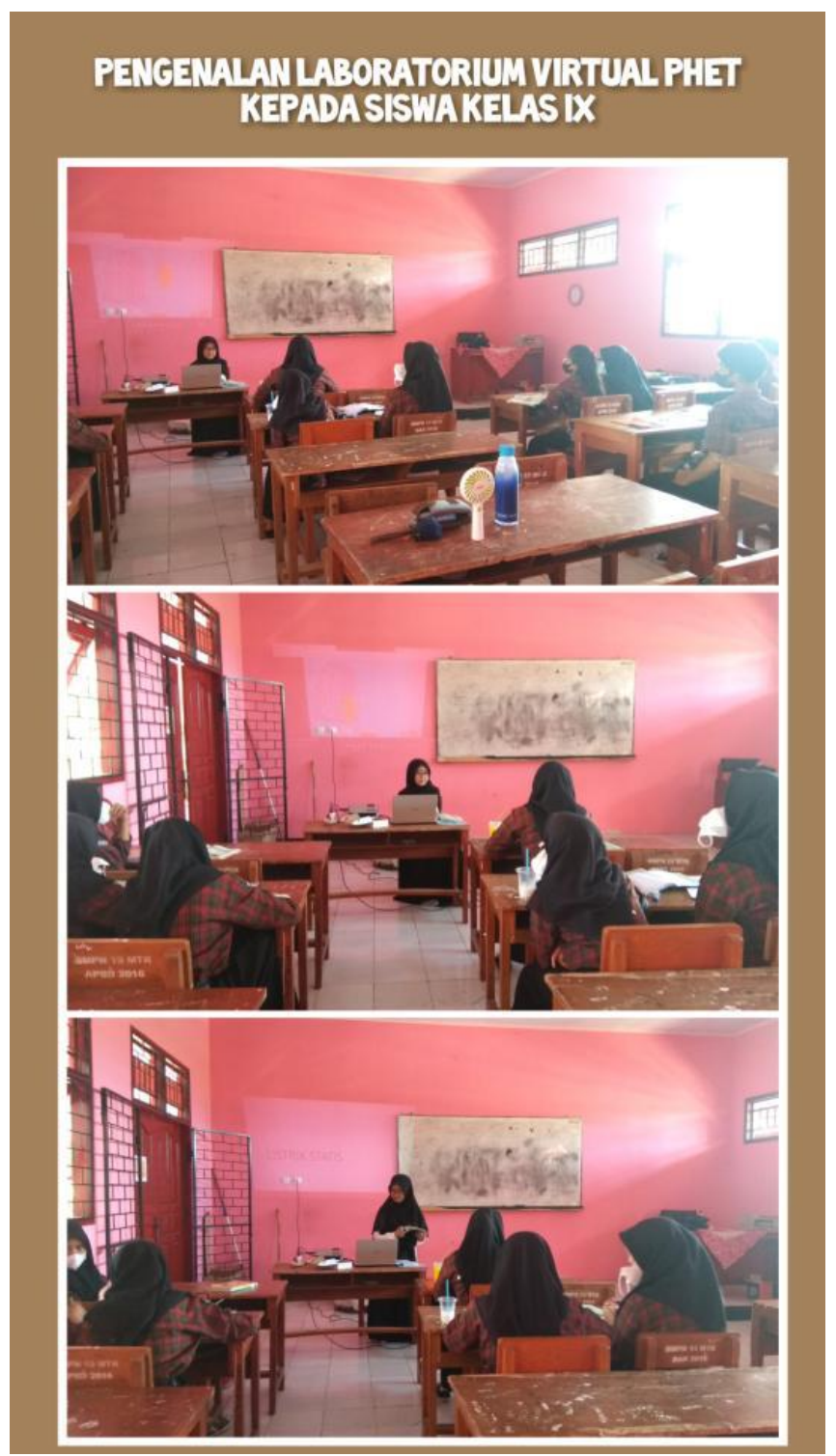

Gambar 3. Dokumentasi pengenalan PhET

Minggu 7 (8-13 November 2021): Kegiatan melatih mengoperasikan Ms word dan excel tetap dilakukan. Dalam hal pengoperasian Ms Powerpoint, siswa sudah mampu menghasilkan suatu presentasi sederhana berupa biodata diri, mengganti background slide, menyisipkan gambar/foto, menambahkan transisi dan animasi, serta menampilkan presentasi yang sudah dibuat menggunakan slide show. Selain itu, beberapa siswa juga sudah mampu membuat folder berisikan hasil kerja mereka selama beberapa minggu ini (dokumen Word, workbook Excel dan presentasi Powerpoint). Beberapa siswa tidak masuk pada minggu sebelumnya, sehingga tim harus mengajarkan ulang materi sebelumnya. Hal ini menyebabkan siswa lain yang sudah mendapatkan materi tersebut untuk menunggu dan tidak melanjutkan ke materi selanjutnya.

Minggu 8 (15-21 November 2021): Pada minggu ini, tim berdiskusi bersama dengan dosen pembimbing, guru mata pelajaran TIK dan guru mata pelajaran IPA tentang rencana untuk minggu selanjutnya, sebagai tindak lanjut dari adaptasi teknologi yaitu penggunaan Microsoft Office (word, excel, dan powerpoint) dan laboratorium virtual PhET. Tim akan melanjutkan untuk membantu siswa dalam adaptasi teknologi sehingga menjadi lebih baik lagi. Tim juga akan melanjutkan pengenalan PhET ke siswa melalui materi Listrik Dinamis. Kegiatan lain yang akan dilakukan oleh Tim terkait dengan Program Kampus Mengajar Angkatan 2 adalah bantuan administrasi untuk bagian Tata Usaha dan perpustakaan, serta mempersiapkan hal-hal yang diperlukan untuk acara lomba Hari Guru ke-76 pada 25 November 2021.

\section{Pembahasan}

Literasi digital diterapkan di sekolah, salah satunya dengan menggunakan media pembelajaran berbasis Information and Technology atau IT (Raihanah et al., 2020). Sembilan bagian dalam dunia literasi digital, yaitu social networking, transliterasy, maintaining privasi, managing digital identity, creating content, organizing and sharing content, reusing/repurposing content, filtering and selecting content, self-broadcasting. Proses literasi digital terhadap anak melalui beberapa tahapan, yaitu: 1) gerakan literasi digital di dalam keluarga 2) literasi digital dalam gerakan literasi sekolah 3) gerakan literasi digital di dalam masyarakat (Mustofa \& Budiwati, 2019).

Kemampuan literasi digital berperan penting dalam menunjang keberhasilan pembelajaran daring akibat pandemi COVID-19. Siswa dengan kemampuan literasi digital yang baik akan berupaya untuk mencari dan menyeleksi informasi yang penting dan memahami, mengkomunikasikan, dan menyampaikan gagasan-gasan dalam ruang digital. Selain itu, kemampuan literasi digital akan membuka kesempatan kepada siswa untuk berpikir, berkomunikasi, dan berkarya yang akhirnya bermuara pada kesuksesan belajar siswa (Falabiba, 2021).

Sejak adanya penerapan kurikulum 2013 (K-13), TIK hanya diajarkan pada Sekolah Menengah Pertama untuk lintas minat atau pendalaman minat bidang teknologi informasi dan komunikasi saja, tidak diwajibkan secara umum. Mengoperasikan komputer merupakan bagian keterampilan hard skill, siswa perlu memiliki ketrampilan dalam mengoperasikan program yang terdapat di Windows dan program yang paling sering digunakan yaitu Microsoft Excel. Microsoft Excel umumnya dikenal sebagai software pengolah angka 
atau bisa dikatakan sebagai program aplikasi lembar yang berfungsi mengolah data secara otomatis seperti perhitungan, rumus, pemakaian fungsi, tabel, pembuatan grafik dan manajemen data untuk menciptakan data informasi digunakan dalam rangka pengambilan keputusan (Zein et al., 2013).

Penggunaan teknologi informasi dengan memanfaatkan penggunaan software aplikasi pengolah kata (Ms word dan ppt) dan data (Ms excel) yang mudah dan powerfull akan mempermudah siswa dan guru untuk melakukan editing materi pelajaran. Oleh karena itu, penggunaan Microsoft Office membantu peran guru dalam memaksimalkan pengetahuan siswa terhadap pelajaran yang disampaikan (Sari et al., 2020).

Terdapat perbedaan yang signifikan antara siswa yang diajar dengan menggunakan media komputer melalui program microsoft power point dan siswa yang diajar dengan menggunakan media komputer melalui program microsoft word. Pembelajaran dengan menggunakan media komputer pada program power point dapat menjadi salah satu alternatif yang bisa dipilih oleh guru dalam menyampaikan materi pelajaran di kelas agar hasil belajar siswa meningkat (Makassar \& Suryani, 2017).

Pengembangan media pembelajaran dan bahan ajar dengan Microsoft PowerPoint perlu dilakukan sehingga materi pelajaran menjadi menarik dan tidak membosankan (Rockhman \& Hendrastomo, 2007). Penggunaan media pembelajaran power point efektif digunakan dalam pembelajaran di SMP (Purwanti et al., 2020). Media lain yang dapat digunakan dalam pembelajaran selain Microsoft Office adalah aplikasi PhET.

Simulasi Physics Education Technology (PhET) adalah suatu simulasi interaktif di internet dengan memakai bahasa pemograman java dan flash, yang dikembangkan oleh tim dari Universitas Colorado Amerika Serikat. PhET adalah simulasi ilmu fisika, ilmu kimia, ilmu biologi, ilmu kebumian dan matematika (Astuti \& Handayani, 2018). Penggunaan media atau virtual laboratory seperti PhET akan melatih kecakapan dan keterampilan siswa dalam menggunakan teknologi (Rasydah et al., 2016).

PhET merupakan rangkaian simulasi interaktif yang sangat menguntungkan dalam pengintegrasian teknologi komputer ke dalam pembelajaran atau eksperimen. Alat dan bahan yang diperlukan yaitu laptop dan software PhET Simulation (Astuti \& Handayani, 2018). Penggunaan PhET sebagai media pembelajaran laboratorium virtual dapat dibantu dengan menyediakan modul pendamping (Asyana \& Arini, 2020). Penerapan PhET dapat meningkatkan minat belajar dan hasil belajar IPA siswa SMP (Heryanti et al., 2021).
Dalam menerapkan media simulasi PhET sebagai guru kita perlu mengondisikan sarana dan prasarana, misalnya ketersediaan komputer di sekolah. Agar maksimal penerapannya dan siswa memahami, dalam pembelajaran tersedia komputer (laptop) dan LCD. Siswa juga sudah mempunyai kemampuan awal (dasar) dalam menggunakan komputer (Rusnita, 2019).

\section{Kesimpulan}

Pelatihan yang diberikan oleh tim pengabdian kepada masyarakat tentang adaptasi teknologi berupa penggunaan aplikasi perangkat lunak ini telah meningkatkan keterampilan siswa SMP dalam menggunakan program komputer. Program komputer yang dimaksud adalah Microsoft Office dan PhET. Kegiatan adaptasi teknologi ini perlu tetap dilakukan agar siswa SMP memiliki literasi digital sebagai bekal untuk bersaing secara global sesuai dengan perkembangan zaman.

\section{References}

Astuti, I. A. D., \& Handayani, S. (2018). Penggunaan Virtual Laboratory berbasis PhET Simulation Untuk Menentukan Konstanta Wien. Jurnal Penelitian Pembelajaran Fisika, 9(2), 66-72. https://doi.org/10.26877/jp2f.v9i2.2487

Asyana, V., \& Arini, A. (2020). Optimalisasi Penggunaan E-Modul Dan Phet Simulation Sebagai Virtual Lab Di Masa Pandemi Covid-19. Komunikasi Fisika Indonesia, 17(3), 160-165. https://doi.org/10.31258/jkfi.17.3.160-165

Darmayani. (2020). Implementasi "Merdeka Belajar" Dalam Dunia Pendidikan Kita. In SMP Negeri 6 Salatiga.

Falabiba, N. E. (2021). Literasi Digital dalam Pembelajaran Daring. Jurnal Eksponen, 11(1), 21217.

Heryanti, A. C., Diah, A. W. L., Fauzia, D. S., Peranginangin, F. Y. B., Mufitdah, N. H., Sitorus, R. M. D., Ginting, N. F., Ardelia, T., \& Adnin, V. (2021). Penerapan Phet untuk Meningkatkan Minat Belajar Siswa Kelas VIII SMPS PTPN IV Bukit Lima Selama Daring. BEST Journal: Biology Education Sciene\& Technology), 4(1), 133-141. https://jurnal.uisu.ac.id/index.php/best/article /view/3854

Junedi, B., Mahuda, I., \& Kusuma, J. W. (2020). Optimalisasi keterampilan pembelajaran abad 21 dalam proses pembelajaran pada Guru MTs Massaratul Mut'allimin Banten. Transformasi: Jurnal Pengabdian Masyarakat, 16(1), 63-72. https://doi.org/10.20414/transformasi.v16i1.196 3 
Makassar, N., \& Suryani, S. (2017). Pemanfaatan Program Microsoft Power Point Dan Microsoft Word Dalam Pembelajaran Tik Di Smp. Juenal Pemanfaatan Program Microsoft Power Point, 20, 117-121.

https://core.ac.uk/download/pdf/304778620.p df

Mustofa, M., \& Budiwati, B. H. (2019). PROSES LITERASI DIGITAL TERHADAP ANAK: Tantangan Pendidikan di Zaman Now. Pustakaloka, 11(1), 114. https://doi.org/10.21154/pustakaloka.v11i1.161 9

Nurhasanah, A., \& Heni, N. (2020). Peran Mahasiswa Program Kampus Mengajar Dalam Meningkatkan Kompetensi SDN 48 Bengkulu Tengah. Prosiding Seminar Nasional Pengabdian Kepada Masyarakatuniversitas Lancang Kuning, 166-173.

http://journal.unilak.ac.id/index.php/SNPKM/ article/view/8066/3378

Pendi, Y. O. (2020). Merdeka Belajar yang Tercermin dalam Kompetensi Profesional Guru Bahasa Inggris SMP Negeri 01 Sedayu. Seminar Nasional Pendidikan, 19, 291-299. http://jurnal.ustjogja.ac.id/index.php/semnas2 020/article/view/7743

Purwanti, L., Widyaningrum, R., \& Melinda, S. A. (2020). Analisis Penggunaan Media Power Point dalam Pembelajaran Jarak Jauh pada Materi Animalia Kelas VIII. Journal Of Biology Education, 3(2), 157. https://doi.org/10.21043/jobe.v3i2.8446

Raihanah, A., Putri, O. R. U., \& Effendi, M. M. (2020). Literasi Digital dan Pemahaman Konsep Himpunan Siswa SMP Menggunakan Media Pembelajaran GUI Matlab. Jurnal Elemen, 6(1), 13-24. https://doi.org/10.29408/jel.v6i1.1309

Rasyidah, K., Supeno, S., \& Maryani, M. (2018). Pengaruh guided inquiry berbantuan phet simulations terhadap hasil belajar siswa sma pada pokok bahasan usaha dan energi. Jurnal Pembelajaran Fisika, 7(2), 129-134. doi:10.19184/jpf.v7i2.7918

Redhana, I. W. (2019). Mengembangkan Keterampilan Abad Ke-21 Dalam Pembelajaran Kimia. Jurnal Inovasi Pendidikan Kimia, 13(1).

Rockhman, M. N., \& Hendrastomo, G. (2007). Pengembangan media pembelajaran dan bahan ajar dengan Microsoft PowerPoint. In Universitas Negeri Yogyakarta.

Rusnita, D. (2019). Pemanfaatan Media Pembelajaran Simulasi Phet (Physics Education And Technology) Dalam Muatan Pembelajaran Ipa Di Sekolah Dasar. Jurnal Pendidikan Bumi Rafflesia 2, 1-
95.

Sari, R., Fitriyani, A., \& Prabandari, R. D. (2020). Optimalisasi Penggunaan MS. Word dan MS. Excel Pada Siswa SMP PGRI Astra Insani Bekasi. Jurnal Pengabdian Kepada Masyarakat UBJ, 3(2), 95-104.

https://doi.org/10.31599/jabdimas.v3i2.184

Septikasari, R. dan R. N. F. (2018). Keterampilan 4C abad 21 dalam pembelajaran pendidikan dasar. Jurnal Tarbiyah Al Awlad, VIII, 107-117.

Sudaryanto, S., Widayati, W., \& Amalia, R. (2020). Konsep Merdeka Belajar-Kampus Merdeka dan Aplikasinya dalam Pendidikan Bahasa (dan Sastra) Indonesia. Kode: Jurnal Bahasa, 9(2), 78-93. https://doi.org/10.24114/kjb.v9i2.18379

Widyastuti, A. (2020). Persepsi Guru Tentang Konsep Merdeka Belajar Mendikbud Nadiem Makarim Dalam Pendidikan Agama Islam Di Mts Negeri 3 Sleman.

Yamin, M., \& Syahrir, S. (2020). Pembangunan Pendidikan Merdeka Belajar (Telaah Metode Pembelajaran). Jurnal Ilmiah Mandala Education, 6(1), 126-136. https://doi.org/10.36312/jime.v6i1.1121

Zein, A., Farizyr, S., Studi, P., Informasi, S., Pamulang, U., \& Selatan, T. (2013). Pengenalan Microsoft Office Pada Siswa Smp Negeri 1 Ciseeng. IV(01), 3639. 